\title{
Failure Analysis to 2000 Liter Capacity Light Filter Tank Wall Filter
}

\author{
Ahmad Zayadi, Cahyono Heri P,Sungkono, Kis Yoga Utomo \\ ${ }^{1}$ Mechanical Engineering Study Program,National University, Indonesia, zayadi@ @ivitas.unas.ac.id \\ ${ }^{2}$ Mechanical Engineering Study Program, National University, Indonesia, cahyono@civitas.unas.ac.id \\ ${ }^{3}$ Nuclear Fuel Technology Center-BATAN, Indonesia, sungkhana@batan.go.id \\ ${ }^{4}$ Mechanical Engineering Study Program,Unkris University, Indonesia, kisyogautomo@ civitas.unkris.ac.id
}

\begin{abstract}
The filter tank wall is one of the main components in the tank. In the event of failure to the tank wall can result in spills and significant impact, which can lead to accidents. The purpose of this study is to obtain the factors that cause failure of the tank wall in soft drinks filter tank capacity of 2000 liters. The method used in this study is testing metallographic using ASTM E 3 and ASTM E 112, hardness testing is done using a standard hardness ASTM E 92 and SNI 19-0409-1989, chemical composition testing using test standard ASTM A 751. Visual observation of the tank filter soft drinks is known to corrosion areas SX-4 SX-6 and SX10. Macrostructure weld joint areas on the tank SX-3 and SX-5 do not look attack ofcorrosion or other defects. Microstructure pieces welding area SX-4 SX-6 and SX-10 form of the austenite phase. The welding hardness area is impaired hardness. The chemical composition of the tank is $0.0142 \% \mathrm{C}$ with other alloying elements $0.224 \% \mathrm{Si}, 1.42 \%$ $\mathrm{Mn}$ and $19.99 \% \mathrm{Cr}$ alloying element composition is known that material SS 304L tank. Failure to the tank filter soft drinks due to crevice corrosion and pitting corrosion[2] [8].
\end{abstract}

Key words: Filter tank, testing mechanics, failure analysis.

\section{INTRODUCTION}

At this time the need for a tank to help smooth the process of processing in the beverage industry is increasing along with the times. The tank is not only a storage place for products and raw materials (liquid or gas) but also keeps the product or raw materials from contaminants. The tank has main components consisting of tank cylinder walls, tank head covers, tank supports, and tank fittings. Tanks can be classified based on functional operation, operating temperature and pressure, material construction, and geometry of the tank[5].

Some liquid storage tanks in industrial environments can suffer Failure due to several factors such as loads, environmental influences, physical conditions, and geographical conditions. These factors cause the tank to malfunction (as liquid storage), namely the possibility of corrosion and cracking at the welded tank plate joint. This can lead to tank leakage which can cause environmental pollution, namely contamination of beverages from corrosion products, financial losses and significant impacts on the industry. One factor of the beverage industry was found to be a failure in the area of the beverage filter tank. In connection with this, then in this final project research will be carried out an analysis of the Failure to the walls of the soft drink filter tank to get the cause of the Failure[6]. The purpose of this research is to find out the factors causing the failure of the soft drink filter tank. Factors causing these failures can be identified by conducting tests which include: Metallographic tests to determine the macrostructure and microstructure in the surface area of the filter tank wall that has been damaged, Hardness test to determine the surface hardness in the area of the filter tank tank that is damaged, Chemical composition test for knowing the chemical composition in the surface area of the damaged tank filter wall[7].

\section{RESEARCH METHODOLOGY}

Research Flow Chart. The flow chart of the research (figure 1) implementation process can be seen in the chartbelow[3]:

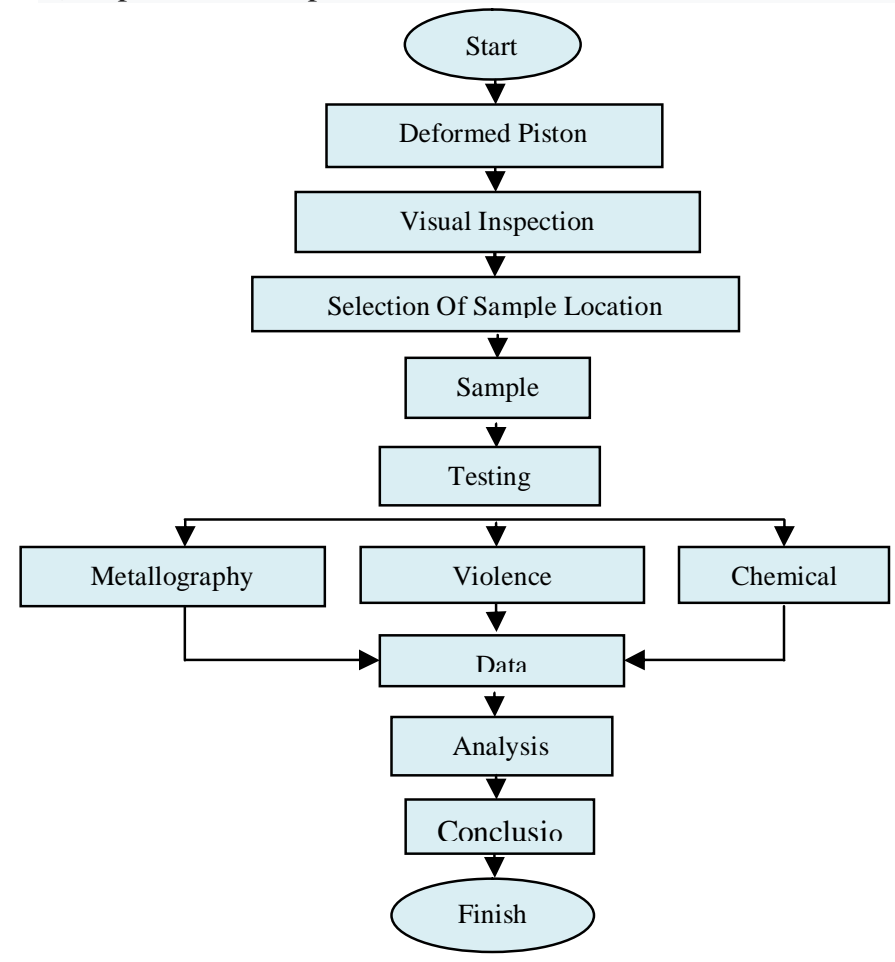

Figure 1: Flow chart of the filter tank failure analysis process of soft drink with the capacity of 2000 liters 


\section{RESULTS AND DISCUSSION}

\section{Macrostructure}

Macrostructure testing is carried out on the damaged area to see the surface of the filter tank. The examination is carried out with an optical microscope.

Figure 2 shows a piece of filter tank wall plate to be used as a test sample[1].

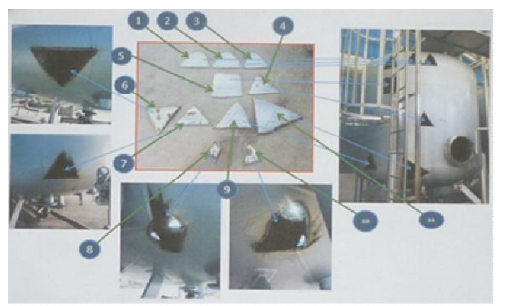

Figure 2 : Pieces of soft drink filter tank wall plates

From several pieces of filter tank walls, only 5 (five) pieces will be tested as shown in Figure 2.

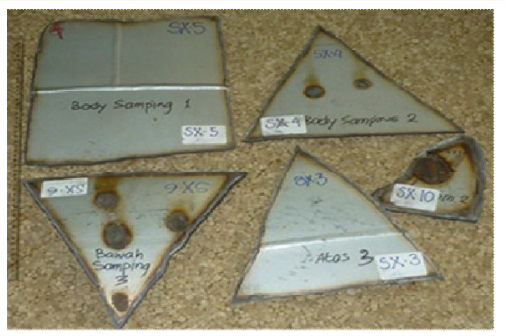

Figure 3 : Pieces of filter tank walls from different places.

Results of the macrostructure examination of 5 (five) pieces of soft drink filter tank walls in different places (figure 3). The selection of the five pieces is based on visual inspection that the sample is focused on the welded joint and the damaged area with code: SX-3, SX-4, SX -5, SX-6 and SX10. On the SX-3 code tank wall pieces, the inside surface of the tank wall does not show any corrosion or other defects while in the SX-4 code tank wall pieces a corrosion attack occurs and there are two welding locations on the inner surface. This corrosion is indicated to spread to form crevice corrosion.

SX-5 code tank wall pieces, no significant corrosion attack was seen, only corrosion stains, while in SX-6 code tank wall pieces, there were 4 (four) welding sites on the inner surface and clearly visible local corrosion attacks. This corrosion is indicated by pitting corrosion in the form of small holes on the inner surface of the tank wall.

SX-10 code tank wall pieces, there are indications of elongated cracks and bulging in the area of Heat Affected Zone (HAZ) and Weld Metal (WM) as shown in the results of macro inspection which shows corrosion attacks occur in the area of Heat Affected Zone (HAZ) and weld metal (WM). Also found fibers in the hole, blackish brown and neatly arranged in the area of the Heat Affected Zone (HAZ) and suspected to be metal phases corroded due to chemicals in the tank.

\section{Microstructure}

Microstructure testing is carried out on 3 (three) tank wall samples which are focused on the welding location and the location of the corrosion attack.

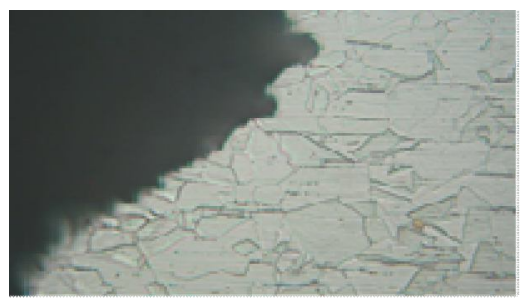

Figure 4 : SX-4 macro and microstructure at 500x micro photo corrosion location of corrosion area

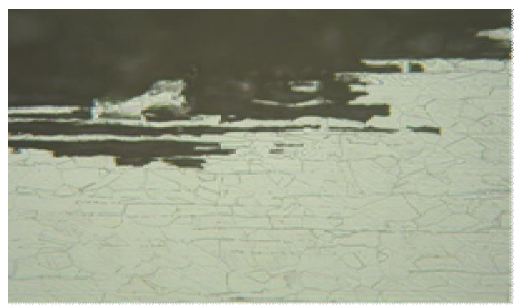

Figure. 5 : SX-6 macro and microstructure at 500x micro photo welding location corrosion area

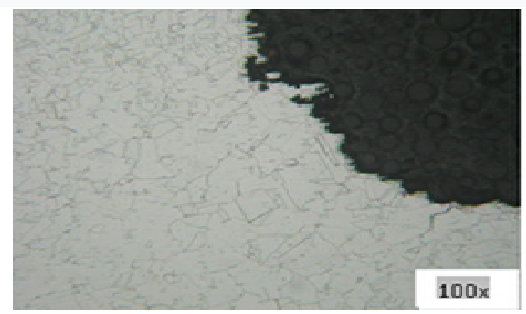

Figure 6 : Microstructure of basic material in the form of austenite andexperiencing grain boundary cracking (intergranular cracking)

The selection of the three pieces is based on visual inspection that the sample is focused on the area of the welding piece and the area that is experiencing corrosion. Microstructure examination results of 3 (three) pieces of soft drink filter tank walls at different welding location pieces with code: SX-4, SX-6, and SX-10 states that the microstructure examination of the SX-4 wall pieces indicated an attack of pitting corrosion and a microstructure in the form of austenite phase dendritic containing ferrite delta at the grain boundary.

In the SX-6 sample, it was clear that the welding process defects in location (1 and 2) were due to imperfections in the process, namely the presence of a corroded tank wall had not been filled with welding material and was still unclean in the grinding process. Microstructure of SX-6 in the form of austenite with a form of corrosion attack that develops on the surface and this corrosion event is considered serious and 
dangerous. Welding defects in SX-6 sample are porosity with a microstructure of welding material in the form of austenite.

At the location of the SX-10 welding piece, fibers were found in the corroded hole, the fibers were blackish-brown and neatly arranged in the hole in the Heat Affected Zone (HAZ) area and indicated as metal phases corroded due to chemical fluids in the tank the. In the micro etching photo, a corrosion attack occurred in the Heat Affected Zone (HAZ) and Weld Metal (WM) areas. Seen in Figure 6, the microstructure of the welding material is in the form of austenite and has grain boundary cracking (intergranular cracking)

\section{Hardness}

Hardness testing of filter tank walls is carried out on 5 (five) samples, namely the welding piece of the tank wall that is damaged and the surface area that is not damaged. Hardness testing of each sample is 5 (five) points. Hardness test samples are shown in the figure 7 below while hardness test data are shown in Table 1[8].

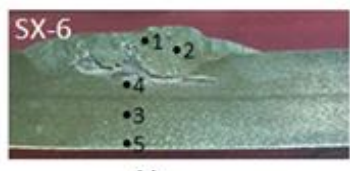

(a)

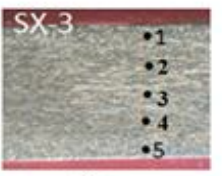

(c)

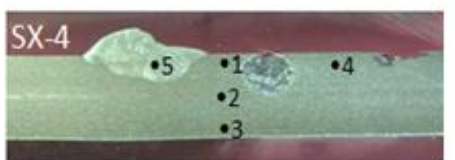

(e)

Figure 7. Hardness of test sample

Table 1: Hardness of the walls of the soft drink filter tank

\begin{tabular}{|c|c|c|c|c|c|}
\hline \multirow{2}{*}{ No. } & \multicolumn{5}{|c|}{ NILAI KEKERASAN, HV (Standax : 228 HV) } \\
\cline { 2 - 6 } & SX-3 & SX-4 & SX-5 & SX-6 & SX-10 \\
\hline 1 & 271 & 225 & 199 & 181 & 175 \\
\hline 2 & 262 & 188 & 210 & 182 & 176 \\
\hline 3 & 271 & 185 & 202 & 225 & 185 \\
\hline 4 & 271 & 199 & 241 & 236 & 161 \\
\hline 5 & 268 & 214 & 232 & 239 & 210 \\
\hline RATA 2 & $\mathbf{2 6 8 . 6}$ & $\mathbf{2 0 2 . 2}$ & $\mathbf{2 1 6 . 8}$ & $\mathbf{2 1 2 . 6}$ & 181.4 \\
\hline
\end{tabular}

Hardness test results of the soft drink tank filter wall of the five samples have significant differences, especially in the area of the Heat Affected Zone (HAZ) as in the SX-4 test mark 5 (five), the value of hardness is below standard (228 $\mathrm{HV}$ ) that is $214 \mathrm{HV}$, in SX -6 test marks 1 and 2, hardness value 181-182 HV and on SX-10 test mark 3 (three), hardness value of $185 \mathrm{HV}$ from the results of all hardness values in the Heat Affected Zone (HAZ) area, it can be seen that the decrease in violence is allegedly due to there is a change in the size of the grains which is getting bigger and equiaxial in the form of a recrystallization mechanism with higher temperatures and longer welding times. At the location of SX-3 pieces the value of hardness exceeds the standard value of hardness because the area of the parent metal is not touched by the welding process, but at SX-5 pieces the value of hardness at test marks 1,2 and 3 has decreased violence allegedly due to the cooling process of welding temperature that is too fast. In Table 1 it is known that the average hardness value ranges from 181.4-268.6 HV.

\section{Chemical Composition}

Using a spectrometer to determine the constituent elements of the tank material. The chemical composition test data of the tank material is shown in Table 2 that the content of the main compounding element of the tank material is $0.0142 \% \mathrm{C}$ with other combined elements $0.224 \% \mathrm{Si}, 1.42 \%$ $\mathrm{Mn}$ and $19.99 \% \mathrm{Cr}$. Based on the composition of the combined elements it is known that soft drink filter tank material made of SS 304L.

Table 2. Data on chemical composition of soft drink filter tanks

\begin{tabular}{|c|c|c|c|r|r|}
\hline No & Unsur & SX-3 & SX-4 & SS 304L & \multicolumn{1}{|c|}{ SS 316L } \\
\hline 1 & $\mathrm{C}$ & 0.0142 & 0.0190 & $\mathbf{0 . 0 3} \mathbf{m a x}$ & $\mathbf{0 . 0 3} \mathbf{m a x}$ \\
\hline 2 & $\mathrm{Si}$ & 0.224 & 0.432 & $\mathbf{0 . 7 5} \mathbf{m a x}$ & $\mathbf{0 . 7 5} \mathbf{m a x}$ \\
\hline 3 & $\mathrm{~S}$ & 0.0003 & 0.00 & $\mathbf{0 . 0 3} \mathbf{m a x}$ & $\mathbf{0 . 0 3} \mathbf{m a x}$ \\
\hline 4 & $\mathrm{P}$ & 0.0169 & 0.0101 & $\mathbf{0 . 0 4 5} \mathbf{m a x}$ & $\mathbf{0 . 0 4 5} \mathbf{m a x}$ \\
\hline 5 & $\mathrm{Mn}$ & 1.42 & 1.52 & $\mathbf{2 . 0 0} \mathbf{m a x}$ & $\mathbf{2 . 0 0} \mathbf{m a x}$ \\
\hline 6 & $\mathrm{Ni}$ & 11.28 & 11.693 & $\mathbf{8}-12$ & $\mathbf{1 0 - 1 4}$ \\
\hline 7 & $\mathrm{Cr}$ & 19.99 & 20.333 & $\mathbf{1 8 - 2 0}$ & $\mathbf{1 6 - 1 8 . 5}$ \\
\hline 8 & $\mathrm{Mo}$ & 1.89 & 1.844 & $\mathbf{2}-\mathbf{3}$ & $\mathbf{2}-\mathbf{3}$ \\
\hline 9 & $\mathrm{~V}$ & 0.095 & 0.1256 & & \\
\hline 10 & $\mathrm{Cu}$ & 1.00 & 0.184 & & \\
\hline 11 & $\mathrm{~W}$ & 0.052 & 0.00 & & \\
\hline 12 & $\mathrm{Ti}$ & 0.01014 & 0.0291 & & \\
\hline 13 & $\mathrm{Al}$ & 0.0173 & 0.02383 & & \\
\hline 14 & $\mathrm{Ph}$ & 0.00 & 0.00 & & \\
\hline 15 & $\mathrm{Nb}$ & 0.0424 & 0.0226 & & \\
\hline 16 & $\mathrm{Zn}$ & 0.0277 & 0.0389 & & \\
\hline 17 & SA & 0.0128 & 0.0078 & & \\
\hline 18 & $\mathrm{Zr}$ & 0.009 & 0.010 & & \\
\hline 19 & Remainder & 63.7557 & 63.7254 & & \\
\hline
\end{tabular}

The results of the chemical composition analysis showed that the walls of the soft drink filter tank are known to be classified as austenitic stainless steel, based on the results of microstructure testing because there is austenite phase. Also, based on the results of macrostructure testing, local failure has occurred that forms fine holes on the surface and is followed by the development of failure that is indicated in the form of local corrosion that occurs in the inner walls with a very aggressive attack. 304L stainless steel is classified as a material that is resistant to corrosion, but some literature suggests that $304 \mathrm{~L}$ stainless steel can be attacked by corrosion due to the presence of chloride ions, excess chlorine, and the presence of oxidants followed by lowcontent chlorine ions. Besides corrosion in water treatment tanks made of stainless steel can be initiated by the formation of sediment or deposits. On the specimen of the filter tank wall specimens, it can be seen that corrosion occurs unevenly, but it is localized in certain areas, so it cannot be said to be an error in the use of chemical liquids and water media during passivation. Also, when viewed from the location of failure to the walls of the light drinking filter tank, no leak was found in the weld area. So it can be 
said that the welding process in tank manufacturing does not cause leaks.

\section{CONCLUSION}

Based on the results of the assessment of metallographic data, hardness and chemical composition of the walls of the soft drink filter tank, it can be concluded as follows:

1. Visual observation of soft drink filter tanks is found that corrosion occurs in SX-4, SX-6 and SX-10 locations.

2. Macrostructure in the weld joints in the SX-3 and SX-5 tanks does not show corrosion attacks or other defects.

3. Microstructure of SX-4, SX-6 and SX-10 welding area in the form of the austenite phase.

4. The hardness of the welding area experiences a decrease in hardness value due to changes in the size of the grain which is getting bigger and in the form of equiaxial grains through a mechanism of recrystallization with higher temperatures and longer welding times.

5. The chemical composition of the tank is $0.0142 \% \mathrm{C}$ with other combining elements $0.224 \% \mathrm{Si}, 1.42 \% \mathrm{Mn}$ and $19.99 \% \mathrm{Cr}$, the composition of the compounding element is known that the SS tank material is $304 \mathrm{~L}$.

6. Failure to the soft drink filter tank is caused by crevice corrosion and pitting corrosion.

\section{REFERENCES}

1) AhmadZayadi, 2019. Piston Failure Analysis OnFourWheeled 1000 CCEngine Cylinder Capacity, Mechanical Engineering. National University, Journal International. IJRTE.

2) American Society Of Materials, handbook Vol 13, Corrosion, 1990.

3) ASTM. Metals Test Methods and Analytical Procedures, Vol 03.01. West Chonshohocken. ASTM International. 2002.

4) ASTM A 380, Standard Test Methods and Definitions for Mechanical Testing of Steel Products, 1987.

5) Aritonang, Padoha. 2010. Planning of Crude Oil Tank with 350 Barrels Capacity in Mangrove Field, Long Strait. Pekanbaru. Riau Islamic University.

6) TirtaNindhia, TjokordaGede. WidyaSemara, I Putu. Adnyana's son, I Wayan. GedeArtana, I Putu. Corrosion Failure Analysis in Hot Water Storage Tanks Made of Stainless Steel. Bali. Udayana University.

7) Atmojo, Setyo. 2012. Designing a 1000 Liter Capacity Water Supply Tank. Yogyakarta. Center for Accelerator Technology and Material Process-BATAN.

8) Setiawan, PututHery. Zacharias, Peter. 2013. Calculation of Thickness and Cap Cover of $1000 \mathrm{MWe}$ PWR Type Nuclear Fuel Element Bubble Tank Reactor for Nuclear Power Plant in Indonesia. PRPN-BATAN, Puspiptek Region. 